\title{
Using the ITS2 transcribed spacer of nuclear ribosomal DNA to identify species of the genus Nitraria
}

\author{
Evgeny V. Banaev ${ }^{1 *}$, Tatiana A. Poliakova ${ }^{2}$, Mariya A. Tomoshevich ${ }^{1}$ and Taigana Ak- \\ Lama $^{1}$ \\ ${ }^{1}$ Central Siberian Botanical Garden of the Siberian Branch of the Russian Academy of Sciences, \\ 630090, Novosibirsk, Russian Federation \\ ${ }^{2}$ Vavilov Institute of General Genetics of the Russian Academy of Sciences, 119991, Moscow, \\ Russian Federation
}

\begin{abstract}
Intragenomic polymorphism of ITS2 of nuclear ribosomal DNA sequences was analysed in 30 samples belonging to Nitraria schoberi, $N$. sibirica. The nucleotide variability of the ITS2 region was detected in the studied Nitraria species as single-nucleotide substitutions (mainly transitions) and single-nucleotide deletion. Five ribotypes of Nitraria were identified in Russia, Kazakhstan and Tajikistan. These ribotypes formed two haplogroups that belong to the species $N$. schoberi and N. sibirica, respectively. The high importance of the discriminatory role of the ITS2 spacer in identifying species of the genus Nitraria is confirmed.
\end{abstract}

\section{Introduction}

The genus Nitraria L. (Nitrariaceae) species are a unique object to study the ways and mechanisms of divergence due to polymorphism and ancient origin. The species major portion is poorly differentiated morphologically; therefore, extreme variants of phenotypic differences are accepted by taxonomists as individual species, intraspecific forms, or ecological races [1-3]. The most widespread and polymorphic species: $N$. schoberi L. and $N$. sibirica Pall. are of great interest. These species cannot always be distinguished; the herbarium specimen identification is difficult [4-5]. Attempts to resolve the taxonomy of Siberian species of the genus Nitraria have been made based on karyological [6], morphological [7] characters, but molecular markers have several advantages over them, demonstrating significant differences at the genetic level without environmental factor participation. The work objective is a comparative analysis of the nucleotide variability of the ITS2 region and identification of its significance in the taxonomy of the genus Nitraria species.

\section{Materials and Methods}

\footnotetext{
*Corresponding author: alnus2005@mail.ru
} 


\subsection{Plant material}

The study material was collected in 2011-2017 in 17 native populations of $N$. sibirica, 13 populations of $N$. schoberi in Russia, Kazakhstan, and Tajikistan. Herbarium specimens are stored in NSK collection (the Dendrology Laboratory Herbarium of the Central Siberian Botanical Garden of the Siberian Branch of the Russian Academy of Sciences) and Digital herbarium CSBG SB RAS (http://herb.csbg.nsc.ru:8081).

\subsection{Genomic DNA isolation, PCR amplification, sequencing}

DNA was isolated from dried leaves by CTAB method [8]. To amplify ITS2 sequences, ITS6 and ITS9 primers were used [9]. A ready-made kit of GenePak ${ }^{\circledR}$ PCR Core reagents (Laboratory Isogen, Ltd, Moscow, Russia) was applied for PCR studies. Sequencing the fragments was made in both directions (Evrogen Joint Stock Company, Moscow, Russia).

The sequencing reaction was performed with BigDye Terminator V. 1.1 Cycle Sequencing Kit. Cleaning products after the sequencing reaction was carried on by the BigDye XTerminator Purification Kit.

The sequences were viewed in Data Collection V. 3.1, and read using the Sequence Analysis Software V. 6. The sequences were pairwise aligned in BioEdit v.7.1.9 software, and multiple alignment was held in the ClustalW2 software followed by checking ambiguous positions at chromatograms and editing manually. The nuclear ribosomal haplotype (ribotype) polymorphism was studied in DnaSP v.6.12.01 software [10]. The haplotype median network was constructed with the Network v.5.0.0.0 software [11].

\section{Results and Discussion}

$N$. schoberi is characterized by larger bushes $-150-170 \mathrm{~cm}$; leaves $-15-30 \mathrm{~mm}$ long and 5.7-8.8 mm wide; seeds - up to $10 \mathrm{~mm}$ long; wider corolla petals - near $2.5 \mathrm{~mm}$, and larger (1.2-1.5 times) anthers. The bush height of $N$. sibirica does not exceed $80 \mathrm{~cm}$, the length of the leaf blade varies from 8 to $15 \mathrm{~mm}$; the seed length is $3.7-7.4 \mathrm{~mm}$; the petal length is slightly more than $3.5 \mathrm{~mm}$; the anthers $-0.5-1 \mathrm{~mm}$ [7].

These species karyotypes differ as well: the predominant chromosome number is diploid $2 \mathrm{n}=2 \mathrm{x}=24$ in $N$. sibirica, the tetraploid chromosome number $2 \mathrm{n}=4 \mathrm{x}=48$ is in $N$. schoberi [6]. At the same time, there is evidence that $N$. sibirica and $N$. schoberi are diploids $(2 \mathrm{n}=24)$, and under phylogenetic analysis of the genus Nitraria based on the combined data of ITS sequences and chloroplast DNA fragments (6 genes) these species are grouped into a clade [12].

The ITS2 spacer contains 273-274 nucleotide sequences, totally 5 phylogenetically informative polymorphisms have been detected in the studied sample ITS2 (4 transitions: C/T, G/A, a transversion: G/C), a single-nucleotide deletion (T/ -), and 2 singletons. Both species specific polymorphisms distinguishing $N$. schoberi and N. sibirica, and intraspecific variability of $N$. sibirica specimens are identified. The revealed differences in the sequences of the intergenic spacer ITS2 in the species $N$. sibirica and N. schoberi correspond to the level of «good» species differences.

Comparative analysis of the sequences of the intergenic ITS2 spacer of nuclear ribosomal DNA in specimens of $N$. schoberi and $N$. sibirica has shown the presence of 5 haplotypes (Fig. 1), which form two haplogroups. H1 and $\mathrm{H} 2$ haplotypes composing one haplogroup, belong to the species N. schoberi; H3, H4, H5 haplotypes are combined into another haplogroup, and all refer to $N$. sibirica. 


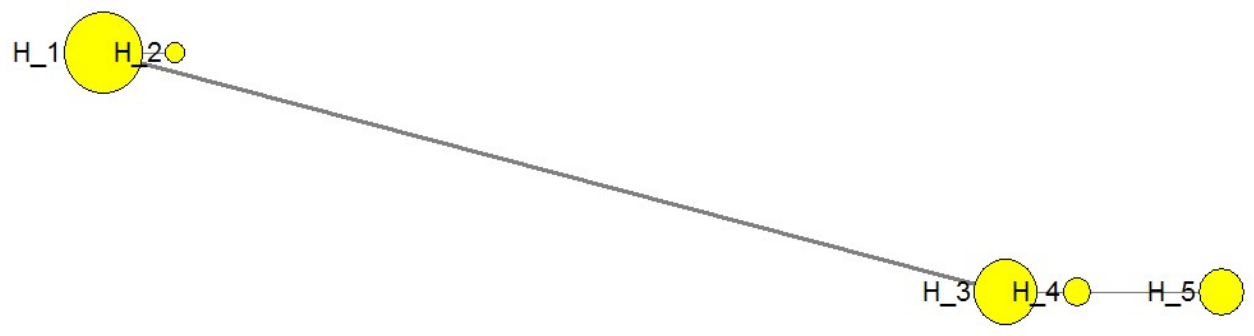

Fig. 1. Median network of the nuclear ribosomal haplotypes based on comparison of ITS2 intergenic spacer sequences in Nitraria samples. Note: H1: N. schoberi (Kulunda, Malinovoe, Bagan, Krim, Aktau, Sariozek, Koktal, Basshi, Balhash, Aidarli, Raz'ezd47, Pyandzh); H2: N. schoberi (Lepsi); H3: N. sibirica (Bele, Kulunda, Rubtsovsk, Noven'koe, Veseloyarsk, Balansor, Yarovoe, Kuchuk, SharaNur, Koktal); H4: N. sibirica (Zhira, Gornyak); H5: N. sibirica (Kurgan, Kainar, Kurti, Basshi, Karatal).

There is no inter-population variability of the $N$. schoberi species in the ITS2 region, since only a single haplotype (H1) is represented in such a wide range of growth (various populations of Siberia, Kazakhstan, Tajikistan, and Crimea) (fig. 2). This study of the ITS2 region divides populations of $N$. sibirica. $\mathrm{H} 3$ and $\mathrm{H} 4$ haplotypes of $N$. sibirica are represented mainly in Siberian populations (Bele, Kulunda, Rubtsovsk, Noven'koe, Veseloyarsk, Balansor, Yarovoe, Kuchuk, Shara-Nur, Zhira, Gornyak), and H5 haplotype is represented in Kazakhstan ones (Kurgan, Kainar, Kurti, Basshi, Karatal).

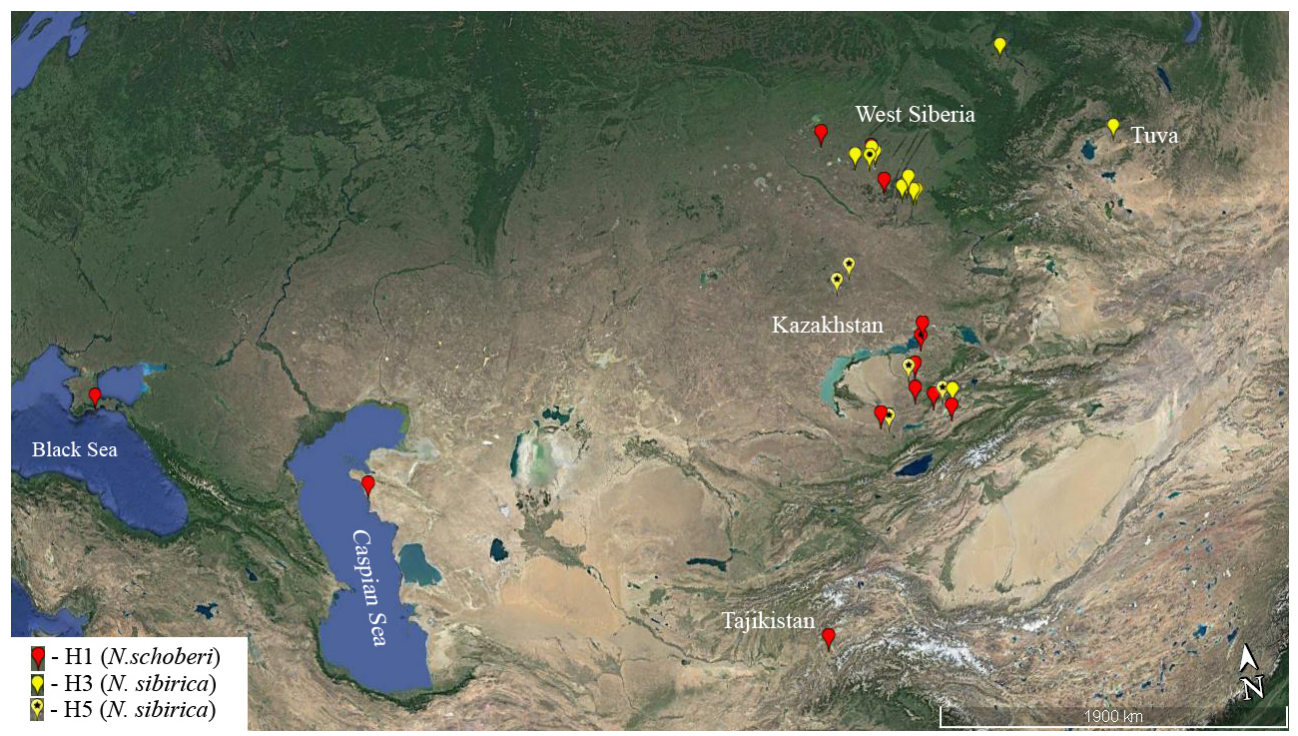

Fig. 2. Distribution of haplotypes of Nitraria schoberi and N. sibirica.

We have previously shown that the Siberian populations of $N$. sibirica are heterogeneous and differentiate on the complex of phenolic compounds into separate groups according to environmental and geographical features, and the gradient of altitude above sea level [1]. The obtained data on the nucleotide variation of the ITS2 region of $N$. sibirica indicate the probable taxonomic heterogeneity of this species. To clarify the results, it's required 
additional comprehensive research, including classical methods (comparative morphological and ecological-geographical).

The research was carried out in the framework of the state assignment of the topics «Analysis of the intraspecific structure of resource plants in Asian Russia, selection and conservation of the gene pool» (number AAAA-A17-117012610054-6) and «Genomic research and genetic polymorphism of cells, organisms and populations» (number 0112-2020-0001).

\section{References}

1. E.V. Banaev, M.S. Voronkova, G.I. Vysochina, M.A. Tomoshevich, Contem. Probl. of Ecol. 8, 735-742 (2015)

2. N.K. Kovtonyuk, M.A. Tomoshevich, E.V. Banaev, Bot. Pacifica 8, 115-118 (2019)

3. M.A Tomoshevich, E.V Banaev, T.A. Ak-Lama, Check List 15, 891-897 (2019)

4. G.A. Peshkova, Family Nitrariaceae, in Flora of Siberia 10, 34-35 (1996). In Russ.

5. I.Yu. Koropachisky, Siberian arboriflora (GEO, Novosibirsk, 2016). In Russ.

6. E.N. Muratova, O.V. Goryachkina, E.V. Banaev, Turczaninowia 16, $50-54$ (2013). In Russ.

7. E.V. Banaev, M.A. Tomoshevich, M.B. Yamtyrov, Contemp. Probl. of Ecol. 10, 664673 (2017)

8. J.J. Doyle, J.L. Doyle, Focus 12, 12-15 (1990)

9. D. Potter, S.M. Still, T. Grebenc, D. Ballian, G. Božič, J. Franjiæ, H. Kraigher, Pl. Syst. Evol. 266, 105-118 (2007)

10. S. Kumar, G. Stecher, M. Li, C. Knyaz, K. Tamura, Mol. Biol. Evol. 35,1547-1549 (2018)

11. K. Tamura, Mol. Biol. Evol. 9, 678-687 (1992)

12. K. Temirbayeva, M.-L. Zhang, Pl. Syst. Evol. 301, 1897-1906 (2015) 